\title{
Design evolution of the diamond window unit for the ITER EC H\&CD upper launcher
}

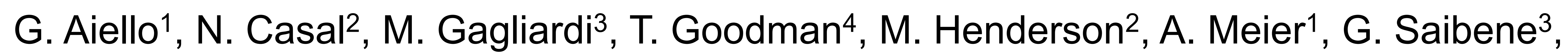

T. Scherer ${ }^{1}$, S. Schreck ${ }^{1}$, D. Strauss ${ }^{1}$

${ }^{1}$ KIT IAM, Hermann-von-Helmholtz-Platz 1, 76344 Eggenstein-Leopoldshafen, Germany

2ITER Organization, Route de Vinon sur Verdon, 13067 St Paul Lez Durance, France

${ }^{3}$ F4E Joint Undertaking, Josep Pla 2, 08019 Barcelona, Spain

${ }^{4}$ SPC, EPFL Station 13, 1015 Lausanne, Switzerland

\section{Motivation}

Design of the torus window unit ready to start the prototyping and testing activity (FDR in 12/2019)
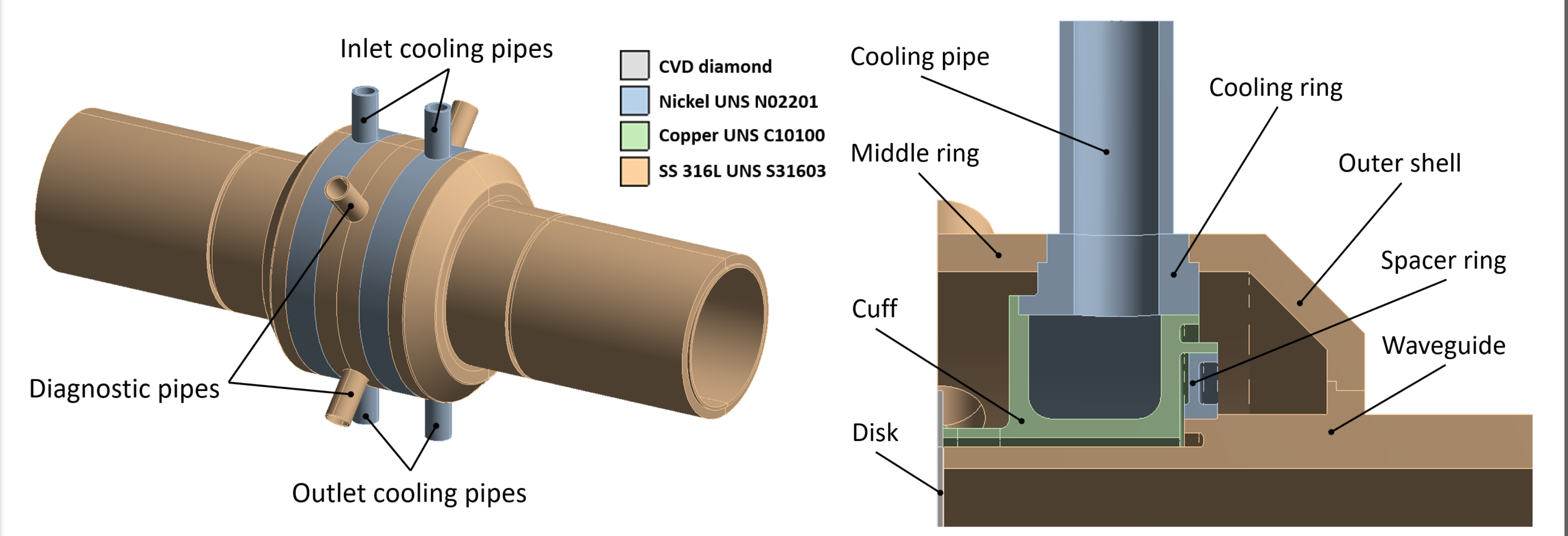

\section{Objectives}

- More feasible and simpler manufacturing and assembling sequence

- Compliance with the requirements of the applicable ASME III-NC code

- Adaptation to the ITER decision of changing the WGs inner diameter from 63.5 to $50 \mathrm{~mm}$ (power density in the Cu-coated WGs 2.6 times greater)
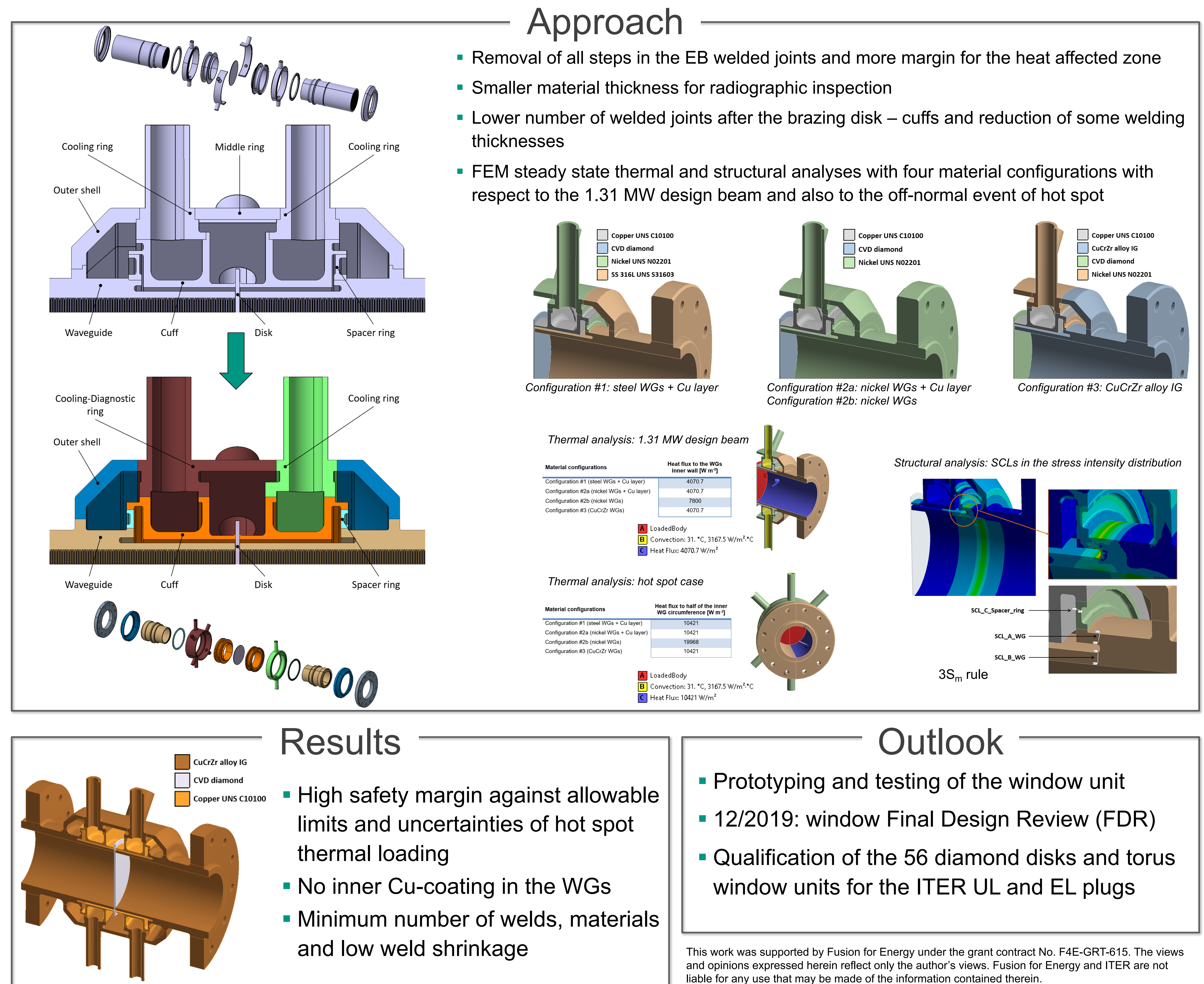

\section{Results}

- High safety margin against allowable limits and uncertainties of hot spot thermal loading

- No inner Cu-coating in the WGs

- Minimum number of welds, materials and low weld shrinkage

\section{Outlook}

- Prototyping and testing of the window unit - 12/2019: window Final Design Review (FDR)

- Qualification of the 56 diamond disks and torus window units for the ITER UL and EL plugs

This work was supported by Fusion for Energy under the grant contract No. F4E-GRT-615. The views and opinions expressed herein reflect only the author's views. Fusion for Energy and ITER are not liable for any use that may be made of the information contained therein. 